National Park, Ontario. Can. Field-Nat., 92: 19-23. - Verme L. J., 1965: Swamp conifer deer yards in northern Michigan. J. For., 63: 523-529. - Wehausen J. D., 1980: Sierra Nevada highorn sheep: history and population ecology. Unpubl. Ph. D. dissert., Univ. Michigan, Ann Arbor. 240 pp. - Wetzel J. F., Wambaugh J. M. \& Peek, J. M., 1975: Appraisal of white-tailed deer winter habitats in northeastern Minnesota J. Wildl. Manage., 39: 59-66.

Accepted, April 14, 1986.

\title{
A Method for Determining Optimum Distance Between Traps on Line Transects
}

METODA OKRESLANIA OPTYMALNEJ ODLEGLOSCI MIEDZY PULAPKAMI W LINII

\author{
S. E. BRAUN HILL \& Daniel F. WILLIAMS
}

Braun Hill S. E. \& Williams D. F., 1986: A method for determining optimum distance between traps on line transects. Acta theriol., 31, 26: $3 \bar{s} 3-358$.

Line transects are often the choice of trap layout for studies of species composition and relative abundance within communities of small mammals. We present a method for determining the optimum distance between traps on lines that will yield a uniform sampling area for each trap and thus maximize catch per effort. The method relies on finding the minimum intertrap distance at which captures are equal in both inner and end traps of short lines. We tested the method in two conifer forest communities of the Sierra Nevada of California. Ten 4-trap lines each of $10-\mathrm{m}, 15-\mathrm{m}$, and $20-\mathrm{m}$ spacing were deplnyed. The optimum intertrap distarce in these communities was $15 \mathrm{~m}$. The method described can be used to determine the optimum distance between traps for other types of studies in other communities.

[Dept. of Ecology and Behavioral Biology, University of Minnesota, Minneapolis, Minnesota 55455 USA; \& Dept. of Biological Sciences, California State University, Stanislaus, Turlock, California 95380 USA]

There is a continuing need for reliable estimates of the diversity and relative abundance of small mammals in various plant communities. This need is most apparent in studies to determine the effects of management practices and to estimate the effects of proposed environmental modifications. Problems arise when designing experiments, to collect the needed data. Chief among these is the method of sampling. Trapping is often the only practical method for determining relative abundance and population structure of most species of small mammals. The type of trap and bait used, the configuration of traps in space, the distance between traps, and the timing and duration of trapping all affect the numbers and kinds of mammals caught. The best trapping design is one that will yield the most accurate information with the least expenditure of time and effort.

Several studies on the relative effectiveness of different traps have 12 - Acta theriologica 
been reported (Andrzejewski \& Rajska, 1972; Brown, 1967; Chełkowska, 1967; Wiener \& Smith, 1972; Williams \& Braun, 1983). The specific goals of a study will often dictate the type of trap used (i.e., live trap or kill trap). In a study whose primary goal is to compare the diversity and abundance of small mammals between different communities, there is no requirement that live animals be released. In this type of study, pitfalls catch a greater diversity and number of small mammals than do either live traps or snap traps (Williams \& Braun, 1983).

The conifiguration of trap positions within an area to be sampled also has received much attention (see Smith et al., 1975 for a review). Each pattern of trap positions presents unique problems of analysis and interpretation of capture data. Traps placed in a straight line generally sample small mammal populations as effectively as those arranged in grids, spirals, octagons, circles, and other patterns. A straight line of traps is not well suited for studies of home range, density, or other attributes of populations, but because it is the easiest configuration to deploy, it is a logical choice where data from captures are used primarily to make comparisons of small mammal diversity among plant communities. Furthermore, many plant communities are narrow (e.g., riparian), especially in mountainous terrain, and a line of traps is frequently the only practical configuration for sampling small mammal populations within these communities.

Optimum spacing between traps is an aspect of experimental design that requires more investigation. Smith et al. (1975) recommended that trap spacing should be based upon the ability of an animal to detect traps (the recognition distance). Calhoun (1964), recommended spacing traps at one-sixth the average diameter of the home range of the dominant species in the community. Without prior knowledge of animals' recognition distances, or the dominance relationships and home range sizes of members of the small mammal community, however, these recommendations are not very useful. Hansson (1967) using a distance of $25 \mathrm{~m}$ found no difference between the average number of animals caught in the end and the inner traps of 10-trap lines in a study of small mammals in a Scandinavian forest. He suggested that this result indicated that $25 \mathrm{~m}$ was greater than the average diameter of the home ranges of the species he studied. He did not, however, test other distances. Optimum spacing between traps obviously must be a compromise, dependent upon a number of habitat-, species-, and age-specific variables, and on the objectives of the study (Gentry et al., 1971; Smith et al., 1975). In order to select an optimum distance for trap spacing, we think that determining the effective sampling area for traps on a line is important. This effective area may relate to recognition distance or 
to average size of home ranges, but the validity of our procedure is not dependent upon confirming these relationships.

We hypothesize that each trap has an effective sampling area which is approximately circular in shape when the habitat and dispersion of small mammals are roughly uniform. If the distance between traps is less than the circle of influence of each trap, the catch in end traps of a line will be greater than the catch in inner traps. This can be visualized as overlapping circles of influence of adjacent traps, with end traps sampling an effectively larger, non-overlapping area than inner traps. The minimum distance at which catches in inner and end traps are equal would be the optimum spacing, and would provide for a uniform sampling area for each trap. Traps spaced at greater distances would have unsampled or less-intensely sampled spaces between adjacent circles of influence, but captures in inner and outer traps would remain unchanged.

Herein we report the results of an experiment designed to determine the effective sampling area for traps arrayed in lines by comparing captures of small mammals in end and inner traps spaced at 10, 15, and $20 \mathrm{~m}$.

This study was conducted at two sites in mixed conifer (1675 m elevation) and red fir $(2300 \mathrm{~m})$ communities of the western Sierra Nevada, Fresno County, California during summer, 1980. At each of two sites, 120 pitfall traps were placed in 30 lines of four traps each. Traps were 7.6-1 plastic buckets buried flush with the ground and one-third filled with water (Williams \& Braun, 1983). Traps were baited by smearing a small amount of peanut butter on the inside of the pitfall just below the rim; bait was reapplied every 2 or 3 days. A $30.5-\mathrm{cm}$ square of plywood ( $0.6 \mathrm{~cm}$ thick), resting on three stakes, was positioned about 10 $\mathrm{cm}$ above the rim of the bucket. This cover reduced evaporative water loss and kept debris out of the trap. Ten lines each had four traps spaced at 10, 15, and $20 \mathrm{~m}$. No two lines were within $30 \mathrm{~m}$; most were greater than $50 \mathrm{~m}$ apart. The forest stages sampled included various canopy cover classes of medium-sized and mature trees, shrub/seedling/sampling, and riparian deciduous stages of mixed conifer and red fir communities. The number and type of stages were approximately equal for each experimental treatment. The microhabitats of each of the four traps of a line were essentially the same.

Traps were operated for a continuous 23-day period in the mixed conifer community. Subsequently, traps were removed and relocated in the red fir community and operated for 14 days. Traps were checked daily and the captives removed, identified, and preserved by standard methods.

A total of 740 trap-nights for each treatment (4440 trap-nights overall) yielded the following results. Captures in inner and end traps for $10-\mathrm{m}$, $15-\mathrm{m}$, and 20-m spacing were, respectively, 47-78, 35-41, 41-41. Species and numbers captured throughout the experiment were: Sorex ornatus (Merrian, 1895) (6), S. monticolus (Merriam, 1890) (52), S. trowbridgii (Baird, 1858) (73), S. tennellus (Merriam, 1895) (10), S. palustris 
(Richardson, 1828) (5), Spermophilus lateralis (Say, 1823) (3), Thomomys bottae (Eydoux \& Gervais, 1836) (2), T. monticola (J. A. Allen, 1893) (5), Reithrodontomys megalotis (Baird, 1858) (17), Peromyscus maniculatus (Wagner, 1845) (59), P. boylii (Baird, 1855) (2), Microtus longicaudus (Merriam, 1888) (38), M. montanus (Peale, 1848) (1), and Zapus princeps (J. A. Allen, 1893) (11).

Because of the potential for animals from neighboring areas to move into the trapping area during the course of a long removal experiment such as this, data from only the first seven days of trapping at each site were examined. Capture results from the two sites were pooled for statistical analysis after insuring homogeneity between the samples. These results were 22 inner 32 outer, 14 inner 16 outer, and 22 inner 15 outer captures for traps at 10-, 15-, and 20-m spacings, respectively. A Chi-square test of these results suggests that traps spaced $10 \mathrm{~m}$ apart may have been interfering with each other. Traps at $15-\mathrm{m}$ and $20-\mathrm{m}$ spacing showed no significant difference betwen captures in inner and outer traps $\left(\chi^{2}=0.13, p>0.50 ; \chi^{2}=1.3, p>0.25\right)$, while traps at $10-\mathrm{m}$ spacing had more captures in outer than inner traps, though this difference was not quite significant at the $p=0.05$ level $\left(\chi^{2}=3.7\right.$, cricital value $=3.8$ for $p=0.05$ ).

There is some conflicting evidence in the literature that long-duration removal studies are biased by an influx of animals from adjacent areas. Stickel (1946) determined "home ranges" of resident animals during a 7-day live-trapping study in a 17 -ac bottcmland forest. She then snap-trapped a 1-ac grid in the center of the larger area for 35 consecutive days. Over the course of the snap-trapping, animals were captured whose "normal" ranges were at succeedingly greater distances from the removal area. Stickel's (1946) results seem to indicate that the area of influence of a trap is not only distance- but also time-dependent. Close examination of her data, however, indicates that the majority of resident animals did not move into the depopulated area. It is thus difficult to evaluate how much of the apparent movement of animals into the depopulated area was actually normal, long-distance movement by resident animals that had been missed during the short live-trapping period. Similar results were obtained by Pucek and Olszewski (1971) who fo nd that 9 days of trapping were insufficient to recapture more than $40 \%$ of individuals marked during a pre-trapping phase. Recently, Mares et $c^{7}$. (1980) have demonstrated that a minimum of 20 captures may be necessary to accurately delineate a home range area. And Bury and C m (pors. comm.) noted that 60 days of trapping were required to c mpile a relatively complete species list for areas of Pacific Northwest forest. 
Given the conflicting evidence of time-dependent trapping bias, wealso analyzed the capture data from the total experimental period. A Chi-square test for homogeneity indicated the appropriateness of pooling the data from the two sites for the $10-\mathrm{m}$ and $15-\mathrm{m}$ spacings, but not for the $20-\mathrm{m}$ spacing (at one site there were more inner than outer captures at $20-\mathrm{m}$ spacing while at the other site the opposite pattern obtained). For the pooled samples, there were significantly more outer than inner captures at $10 \mathrm{~m}\left(\chi^{2}=7.68,1\right.$ d.f., $\left.p<0.01\right)$, but not at $15 \mathrm{~m}$ $\left(\chi^{2}=0.65,1\right.$ d.f., $\left.p>0.25\right)$. In addition, if we examine the pattern of inner and outer captures for each line of 4 traps, only at $10-\mathrm{m}$ spacing do we find significant differences $\left(\chi^{2}=16.85,9\right.$ d.f., $\left.p<0.05\right)$. Additionally, for the three most abundant species (S. trowbridgii, S. monticolous, and $P$. maniculatus) we found the same pattern of more captures in end traps spaced at $10 \mathrm{~m}$, but nearly equal numbers of captures in traps. spaced at 15 and $20 \mathrm{~m}$.

The total captures in lines spaced at $10 \mathrm{~m}$ is greater than the totals: for the other spacings. This can be explained most parsimoniously by differences in microhabitat in which the different lines were placed. Although we atempted to place each treatment equally in the different. habitat types and forest-cover stages this was not always possible. In some lines of 4 traps we captured large numbers of small mammals. while in other lines we captured none. The microhabitats of each of the four traps in a line were essentially the same. however, thus thecomparison of captures within lines is most appropriate.

The results of this experiment provide empirical support for a minimum intertrap distance of $15 \mathrm{~m}$ on line transects in removal studies in conifer forest communities. Matters of experimental design often require compromises, and in this study we were looking for the best compromise distance between traps on transects in all forest types of the Sierra Nevada. We had strong, although not statistically significant, evidence after 7 days that traps spaced $10 \mathrm{~m}$ apart interferred with each other, while traps spaced farther apart did not. The evidence was more compelling after longer periods of time. Because the best compromise is that design which maximizes return while minimizing effort, we would suggest $15 \mathrm{~m}$ as an optimal distance between traps in these conifer forest communities. Other minimum (optimum) intertrap distances for either removal- or live-trapping may be required in plant communities that differ significantly in structure or species composition from the communities we were studying. The optimum distance between traps: would also vary if data were required on a particular species rather than on all species simultaneously. The experimental procedure employed in this study, or a similar one modified for live-trapping should yield: 
the information needed to determine the optimum distance between traps for other types of studies.

Acknowledgements: The field work was accomplished with equipment and support of the USDA Forest Service, Pacific Southwest Forest and Range Experiment Station. Dr. Jared Verner provided helpful suggestions and criticism in the development of the experiment. Kent E. Brown, J. Alistair Hamilton, Robert J Reiter, and Gerard G. Rogers assisted with all aspects of the field work. We are grateful for their hard work for so little remuneration. Kerry S. Kilburn and anonymous reviewers provided suggestions for improvement of the manuscript.

\section{REFERENCES}

Andrzejewski R. \& Rajska E., 1972: Trappability of bank voles in pitfalls and live traps. Acta theriol., 27: 41-56. - Brown L. N., 1967: Ecological distribution of six species of shrews and comparison of sampling methods in the central Rocky Mountains. J. Mammal., 48: 617-623. - Calhoun J. B., 1964. The social use of space. [In: "Physiological mammalogy", W. Mayer, R. Van Gelder, eds.] Academic Press: 1-381. New York. - Chelkowska H., 1967: An attempt at comparing two methods of trapping small rodents (in pitfalls and live traps). Ekol. Polska, ser. A, 15: 779-785. - Gentry J. B., Golley F. B. \& Smith M. H., 1971: Yearly fluctuations in small mammal populations in a southeastern United States hardwood forest. Acta theriol., 16: 179-190. - Hansson L., 1967: Index like catches as a basis of population studies on small mammals. Oikos, 18: 261-276. - Mares M. A., Willig M. R. \& Bitar N. A., 1980: Home range size in eastern chipmunks, Tamias striatus, as a function of number of captures: statistical biases of inadequate sampling. J. Mammal., 61: 661-669. - Smith M. H., Gardner R. H. Gentry J. B., Kaufman D. W. \& O'Farrell M. H., 1975: Density estimations of small mammal populations. [In: "Small mammals: their productivity and population dynamics", F. B. Golley et al., eds.] Cambridge Univ. Press: 25-53. London. - Stickel L. F. 1946: The source of animals moving into a depopulated area. J. Mammal., 27: 301-307. - Wiener J. G. \& Smith M. H., 1972: Relative efficiences of four small mammal traps. J. Mammal., 53: 868-873. - Williams D. F. \& Braun S. E., 1983: Comparison of pitfalls and conventional traps for sampling small mammal populations. J. Wildl. Manage., 47: 841-845.

Accepted, June 28, 1985. 